\title{
Clínica da atividade e análise institucional: intercessões possíveis
}

Claudia Osorio da Silva ${ }^{1}$

Fernanda Spanier Amador ${ }^{2}$

Tatiane Oliveira $^{3}$

\section{Resumo}

O artigo explora possíveis intercessões da clínica da atividade com princípios e conceitos da análise institucional, tendo como pressuposto que há, entre essas abordagens, uma base epistemológica comum, na qual se destacam a importância do princípio de transformar para conhecer e o foco da análise nas tensões que habitam o campo analisado. O principal objetivo deste texto é produzir entrelaçamentos teórico-metodológicos que possam levar a uma ampliação do campo da clínica do trabalho e, em especial, da clínica da atividade. Pensar a experiência do trabalho dando relevo ao universo normativo e às tramas institucionais que a atravessam possibilita, entre outros efeitos, alcançar, na análise, questões atuais como aquelas da interferência do racismo e das lutas antirracistas nos gêneros de atividade em foco.

Palavras-chave: Trabalho; Atividade; Gênero de Atividade; Pesquisa-Intervenção.

\section{Clinique de l'activité et analyse institutionnelle : intercessions possibles}

\section{Résumé}

L'article explore les intercessions possibles avec les principes et les concepts de l'analyse institutionnelle, en supposant qu'il existe, parmi ces approches, une base épistémologique commune, dans laquelle se détachent l'importance du principe de transformer pour comprendre et le focus de l'analyse sur les tensions qui habitent le terrain analysé. L'objectif principal de ce texte est de produire des intercessions théorico-méthodologiques pouvant conduire à un élargissement du champ de la clinique du travail et, en particulier, de la clinique d'activité. Réfléchir à l'expérience de travail, mettre en valeur l'univers normatif et les rapports institutionnelles qui le traversent, permet, entre autres effets, d'atteindre, dans l'analyse, des problématiques d'actualité comme celles du racisme et des luttes antiracistes dans les genres d'activité visés.

Mots-Clés: Travail; Activité; Genre d’Activité; Recherche-Intervention.

\section{Introdução}

Fazer o entrelaçamento de abordagens conceituais e metodológicas é sempre um bom e grande empreendimento. Entendemos que a possibilidade de produzir conexões com outros

\footnotetext{
1 Departamento de Psicologia e do Programa de Pós-Graduação em Psicologia/UFF, Niterói, RJ E-mail: claudia.osorio.uff@gmail.com.

${ }^{2}$ Departamento de Psicologia Social e Institucional/Instituto de Psicologia e do Programa de Pós-Graduação em Psicologia Social e Institucional/UFRGS, Porto Alegre, RS.

${ }^{3}$ Secretaria da Saúde do RS, mestranda do Programa de Pós-Graduação em psicologia Social e Institucional/UFRGS, Porto Alegre, RS.
} 
campos de saber é constitutiva da clínica da atividade. É por meio desse entrelaçamento, ou desses processos de intercessão entre abordagens teóricas, que ferramentas conceituais e métodos clínicos de intervenção no trabalho podem se ampliar. Intercessão, aqui, é tomada no sentido deleuziano, como "relações de ressonância mútua e em relação de troca" (DELEUZE, 1992, p.156). Por esse processo, o operar com uma abordagem percute em outras e propicia enveredar por novos caminhos.

Alguns pressupostos conceituais são comuns e transversais às diferentes abordagens que tomamos neste artigo. Dentre eles destacamos: uma concepção da vida, e da vida no trabalho, como luta, como um campo de disputas; e uma concepção de humano como ser que cria um meio para viver, em diálogo com outros humanos e coisas.

Esse diálogo se dá, atualmente, a partir do modo de produção capitalista neoliberal. Se tomarmos essa dimensão processual e criadora da vida e, principalmente, dos humanos, o neoliberalismo é mais uma modulação do capitalismo que vem responder às lutas que trabalhadores e trabalhadoras empreendem. É necessário que o capitalismo se module para que possa permanecer e se fortalecer. Logo, não se trata de um modo natural de existência, um modo natural de governo, pois não existiu sempre. Não se trata de uma situação natural à qual temos que nos adaptar, uma vez que se adaptar não é natural da condição humana. Ao contrário, afirmamos que a marca dos humanos é, sim, sua potência criadora e insubmissa a qualquer determinação heterônoma.

Chegamos, então, aos pressupostos éticos, pressupostos dos valores que nos movem, que são a vida - no caso a vida humana. Entendemos que sua direção prioritária e essencial é a de fabricar mundos com os outros, atuando em comunhão, de modo coletivo. Precisamos de coletivos fortes com valores comuns definidos conjuntamente.

Assim, contra uma produção de subjetividade que naturaliza um modo de subjetivação individualizado, contra a competição como um modo 'natural' e desejável e o lucro como valor central, opomos o valor da vida e a valorização dos coletivos, do diálogo lateralizado, sem hierarquias desqualificadoras e da colaboração conflitual, como caminho desejável. Este é o objetivo da clínica da atividade, no nosso entendimento: contribuir para o desenvolvimento de coletivos, visando como valor à vida e à saúde no sentido dado por Georges Canguilhem (2012).

Nessa mesma direção ético-política, temos como uma das linhas teórico-clínicas das 
formulações em clínica da atividade a proposta de Ivar Oddone e colegas (1981) e outros colegas italianos, com princípios éticos que se mantêm ainda hoje, mas que exigem novas estratégias de luta em tempos de neoliberalismo. Portanto, desses pressupostos que inauguram a clínica da atividade, faz parte a valorização do diálogo entre saberes advindos da experiência concreta de trabalhadores e trabalhadoras e dos científicos e/ou dos acadêmicos. Nesse diálogo, em que o protagonismo da experiência é pré-requisito ético e metodológico, busca-se provocar a análise do trabalho.

Partindo daí, em nossa atuação em clínica da atividade, vimos buscando desenvolver métodos, a partir de outras intercessões, que nos parecem bastante frutíferas para essa tarefa de produzir entrelaçamentos teórico-metodológicos que possam ter como efeito a ampliação do campo da clínica do trabalho - em especial, neste texto, com a clínica da atividade. Esse é o principal objetivo deste artigo.

Assim, tomamos os princípios e conceitos da análise institucional de linhagem francesa, principalmente com autores como René Lourau (1993) e Felix Guattari e Sueli Rolnik (2013), como potentes intercessores para esse empreendimento. A aproximação com a análise institucional é algo que faz parte da história da psicologia social no Brasil e emerge na década de 1970. Entendemos que há, entre essas abordagens, uma base epistemológica comum, da qual destacamos a importância do princípio de transformar para conhecer e o foco da análise nas tensões que habitam o campo analisado. Vamos explorar a seguir algumas possibilidades desse caminho.

\section{Transformar para conhecer}

Para aceder aos processos de produção de subjetividade em sua relação com o trabalho, temos tomado como uma de nossas ferramentas o conceito de atividade tal como ele vem sendo desenvolvido por Yves Clot, bem como pela Equipe de Psicologia do Trabalho e Clínica da Atividade (CNAM - Paris). Nessa linha teórico-metodológica, a atividade (de trabalho) é sempre mais do que o gesto realizado, observável diretamente, mensurável para fins de avaliação de produtividade.

O conceito e, portanto, a análise da atividade, inclui, além do que é efetivamente realizado, o que não é feito, o que é feito para não fazer, o que se gostaria de fazer e o que 
deveria ser feito (CLOT, 2010). Assim, munidas dessa concepção do trabalhar, analisamos a atividade que se realiza como atividade situada, coletiva e necessariamente inovadora, o que não impede que seja por vezes limitada em sua capacidade de desenvolvimento.

Nessa perspectiva, interessam-nos métodos de intervenção que possam produzir uma ampliação do poder de agir dos trabalhadores, o que supõe a produção de sujeitos capazes de reinventar formas de enfrentar novas e velhas situações, utilizando-se para isso de sua própria experiência. Do nosso ponto de vista, os dispositivos utilizados na análise do trabalho devem incidir sobre a experiência de trabalho dos sujeitos envolvidos, como participantes de um determinado ofício, de modo a transformá-la, tornando-a útil na construção de novas experiências.

Na clínica da atividade, subjetividade e atividade são produtos e produtores em um mesmo processo, dado que os recursos coletivos para a ação, historicamente produzidos como recursos de ofício e de gênero de atividade profissional nunca são completos ou prontos, devendo ser reinventados na situação, isso porque os processos de singularização desses recursos se dão permanentemente. A capacidade de agir está, então, diretamente relacionada à capacidade de ser afetado pelas variações na situação de trabalho (CLOT, 2010).

Na metodologia histórico-desenvolvimental, retomamos a diferença feita por Vigotski já em 1925 entre comportamento realizado e desenvolvimento possível (CLOT, 2004). O comportamento é um sistema de reações que foram vencedoras entre diferentes ações possíveis naquela situação. Aquilo que é realizado é apenas uma parte ínfima do que seria possível fazer. “Mas essas possibilidades abandonadas - que não são diretamente acessíveis, nem pelo sujeito nem por seu interlocutor - não deixam de agir" (CLOT, 2004, p.7). Para retomá-las, é preciso adotar uma metodologia indireta, que consiste na "experiência vivida de um objeto em objeto de uma nova experiência vivida" (VIGOTSKI [1925] apud CLOT, 2004, p.7).

Nesses termos, é proposta nessa metodologia uma forma de coanálise do trabalho, praticada no ambiente habitual de trabalho. A pesquisa é sempre clínica, uma vez que é situada e deve produzir efeitos de desenvolvimento de recursos para a ação. O exercício de uma clínica da atividade supõe a instalação proposital de um dispositivo desenvolvimental: a organização de uma nova atividade se superpõe à atividade ordinária que se busca transformar e compreender, ou melhor, transformar como indispensável para compreender. 
A fim de desenvolver tais dispositivos de intervenção, tomamos o conceito de analisador (LOURAU, 1993; GUATTARI, ROLNIK, 2013), que se refere aos fatos e às situações que emergem - de forma imprevista, ou não, uma vez que podem ser construídos pelo analista - no processo de intervenção e que viabilizam a identificação de aspectos contraditórios e não explicitados de um grupo, bem como da organização na qual os participantes se inserem. A análise é feita, portanto, pelo analisador que funciona como um dispositivo de análise.

Nessa perspectiva, é operada uma inflexão importante, pois a análise é feita pelo analisador - construído pelo analista ou por um fato intempestivo - e não pelo analista. A análise emerge, assim, nos diálogos; não é fruto de expertise. Cabe ao analista sustentar os tensionamentos, sustentar o dispositivo de análise, o diálogo em que controvérsias podem comparecer. Sustentar controvérsias é objetivo e também meio de desenvolvimento de recursos para a atividade. Nas palavras de Clot:

No campo do trabalho, o interesse da tradição ergonômica francofônica (Béguin, Weil-Fassina, 1997) está em insistir no fato de que compreender se destina a transformar. $\mathrm{O}$ que nós descobrimos é talvez a profundidade do que aí se levanta. Isso porque, para compreender o que buscamos compreender, é preciso transformar (CLOT, 2004, p.7). ${ }^{4}$

O objetivo de transformar as relações entre processos de trabalho e processos de produção de subjetividades é motivado pelo reconhecimento de uma obrigação ética. Todos aqueles que estão em posição de intervir nas instâncias coletivas, favorecendo a produção de novos sujeitos autônomos, regulados pela lógica da saúde e da vida, não podem se esquivar de trabalhar por essa proposta ético-política.

Por subjetividades, entendemos os modos de pensar, agir e sentir que são tanto pessoais quanto coletivos; são historicamente produzidos e nos atravessam, num entrecruzamento sempre singular. Nessa concepção, não há dicotomia entre individual e grupal, ou individual e coletivo: os valores coletivos atravessam a cada um de nós, em configurações singulares e jamais congeladas em formas acabadas.

\footnotetext{
${ }^{4}$ Dans le champ du travail, l'intérêt de la tradition ergonomique francophone (Béguin, Weil-Fassina, 1997) est d'avoir insisté sur ce fait que comprendre est destiné à transformer. Ce que nous découvrons, c'est peut-être la profondeur du problème ainsi soulevé. Car, alors, pour comprendre ce que nous cherchons à comprendre, il faut transformer.
}

Periódico Horizontes - USF - Itatiba, SP - Brasil - e021032 
O objetivo de transformar também é motivado pela necessidade de tornar visível o real da atividade, possibilidades outras do trabalhar, já que aquilo que é realizado é apenas uma parte ínfima do que seria possível fazer. Nesse processo, criam-se, na pesquisa-intervenção, novos meios de trabalho e novos meios de pesquisar o trabalho.

Essa dinâmica nos coloca a questão: como se dão as relações entre pesquisa e intervenção em clínica da atividade? Em entrevista concedida por Yves Clot a Guy Jobert, este tema é abordado, tal como podemos ler na citação que segue.

O trabalho conjunto com nossos interlocutores, no campo empírico, permite enriquecer a gama de possibilidades da ação humana, descobrir aquilo que, até então, era inimaginável. Aí o desenvolvimento é método de produção de resultados práticos eventualmente impensáveis até aquele momento. Provocando o desenvolvimento podemos estudá-lo. Mas aí a ação no campo muda de estatuto para se tornar recurso para uma outra ação, a pesquisa em si mesma. Seu objeto é aquilo que se passou e que não poderíamos alcançar senão do ponto de vista de uma outra ação: a produção de conhecimentos sobre o desenvolvimento, o que é também um exercício original. Esse exercício se pratica no campo da história das disciplinas, com esses debates de escola, seus problemas científicos também difíceis de resolver (CLOT, 2008, p.69). ${ }^{5}$

Seriam pesquisa e intervenção atividades concorrentes? A solução para a possível concorrência entre a atividade de intervenção e a do desenvolvimento de ferramentas conceituais não pode estar no simples arranjo temporal. Como fazer para se desembaraçar da ação de produção conceitual durante a intervenção para não permitir que uma ação seja impedimento para a outra? A intervenção é fonte e recurso (em francês source e ressource) tanto da atividade de pesquisa quanto da clínica. Tendo esses questionamentos em vista, precisamos pensar recursos para melhor manejar essas relações. Como sustentar os múltiplos diálogos que aí se dão?

Não devemos pôr obstáculo à emergência das ideias. É importante que o clínico-

\footnotetext{
${ }^{5}$ Le travail conjoint avec nos interlocuteurs sur le terrain permet d'enrichir la gamme des possibilités de l'action humaine, de découvrir ce qui, jusqu'ici, était inimaginable. Là, le développement est méthode de production de résultats pratiques éventuellement impensables jusque-là. Du coup, ainsi provoqué, on peut l'étudier. Mais là, l'action de terrain change de statut pour devenir moyen d'une autre action, la recherche elle-même. Son objet est ce qui s'est passé et qu'on ne peut saisir que du point de vue d'une autre action : la production de connaissances sur le développement qui est aussi un sport original. Il se pratique sur le terrain de l'histoire des disciplines avec ses débats d'école, ses problèmes scientifiques difficiles à résoudre eux aussi.
} 
pesquisador esteja sensível às provocações do campo empírico. Pensamos, assim, recorrer à proposição do diário de campo, nos moldes da análise institucional, para recolher as reflexões, os fios soltos, os possíveis eixos para o desenvolvimento teórico resultante do diálogo interior que se dá no diálogo com o campo, com o saber da experiência.

O diário de campo (LOURAU, 1993) funciona como instrumento que permite ao pesquisador se desvencilhar momentaneamente do impedimento provocado pela convocação a tarefas diferentes que podem interferir umas nas outras. Nesse diálogo consigo mesmo, feito por intermédio do diário de campo, o plano da análise e o da intervenção se alternam em graus de intensidade, evitando que a intensificação de um se faça impedimento ao outro. Trata-se de um diálogo em que se fazem presentes muitas vozes, vozes que trazem enunciados institucionais, historicamente produzidos, e enunciados fortemente situados, produzidos coletivamente.

Assim, a escrita, no trabalho do clínico/pesquisador, toma a função de provocar uma intensificação do diálogo interior do pesquisador. A escrita se inicia pelo diário de campo e se intensifica nos textos científicos e nos debates entre pares (OSORIO DA SILVA, 2016). Vamos, assim, fabricando nossa caixa de ferramentas: a partir de múltiplas referências, construímos um novo campo de coerências (LOURAU, 1993).

De fronteira tênue, os objetos da Análise Institucional (Al) e da Clínica da Atividade (CA) se encontram. Afinal, como pensar a experiência do trabalho sem passar, necessariamente, pelo universo normativo que os enlaça em tramas institucionais? Essa pergunta move nosso interesse em produzir ferramentas conceituais clínicas do trabalho que catalisem a análise do plano institucional implicado nos processos de subjetivação e de saúde, de trabalhadores e trabalhadoras, em diferentes contextos.

"O que quer a Análise Institucional?" perguntam as prefaciadoras do conhecido livro "Grupos e Instituições em Análise". Elas respondem: "Em primeiro lugar, o que a movimenta, o que a coloca em processo não é uma vontade de atingir a verdade, mas a vontade política de produzir novos problemas" (RODRIGUES; LEITÃO; BARROS, 1992, p.12). Ela convoca, antes de tudo, a um exercício aprendente, de si, do outro e com o outro, de maneira a revitalizar-se, nela mesma, enquanto ofício (CLOT, 2010, 2013a), isto é, enquanto trabalho cultivado por entre as forças, coletivamente. 
A fecundidade entre esses dois campos, Al e CA, vem sendo explorada, especialmente, por pesquisadores brasileiros (SILVA; ZAMBONI; BARROS, 2016; OSORIO DA SILVA, 2020), ainda que também sinalizada por certos clínicos do trabalho, dentre os quais destacamos Yves Clot (2010). Nesse percurso, destacam-se as contribuições de François Tosquelles (2009), a partir de suas experiências no campo da desinstitucionalização das práticas psiquiátricas.

Para posicionar nossa perspectiva de operar pelo "entre" Al e CA, trazemos o psiquiatra catalão, a partir de seu escrito "O Trabalho terapêutico no Hospital Psiquiátrico", abordando a presença da temática das instituições na perspectiva do trabalho tomado como atividade e suas conexões com a saúde até chegar a considerações a respeito do livro intitulado "Clínicas do Trabalho e Análise Institucional" (SILVA; ZAMBONI; BARROS, 2016), que reúne textos diversos operando instigantes modulações conceituais nesse terreno.

A partir daí propomos a consideração do procedimento analítico-institucional e clínico da atividade como exercício problematizador que procede por análise de implicação, fazendo da própria CA o caso, ou seja, tomando a própria CA como objeto da atividade de análise. Nesse caminho, vamos nos defrontar com indagações a respeito de questões-problema de grande importância, tais como as questões raciais implicadas na dinâmica gênero e estilo, a qual diz respeito a aspectos relativos ao necessário exercício descolonizador do pensamento no âmbito clínico do trabalho.

\section{A potência do trabalho como ofício para os processos de análise-intervenção institucional}

François Tosquelles, psiquiatra catalão com atuação no chamado período da psicoterapia institucional, lutou na Guerra Civil espanhola, tendo sido durante um período médico-chefe dos serviços psiquiátricos do Exército, momento em que criou uma Comunidade Terapêutica em Almodóvar del Campo. Posteriormente, a partir de 1941, na França, trabalhou na Clínica SaintAlban em Lozère, onde teve a oportunidade de vivenciar "um intenso campo de experimentações de novas formas de organização do hospital e do trabalho terapêutico" (RUIZ et al., 2013, p.858). Apresenta como seu propósito, fazer trabalhar os doentes e o pessoal cuidador para cuidar da instituição (TOSQUELLES, 2009).

Tosquelles destacava as possibilidades de transformação institucional para tratamento 
de pessoas em sofrimento psíquico e ressaltava o lugar do trabalho em tais processos, aspecto esse caro aos propósitos deste artigo. Tosquelles não considerava as atividades laborais dos doentes mentais como pseudoprodutivas ou orientadas por relações e rotinas meramente internas, e sim como possibilidades de intercâmbio com o meio social, possibilitando trocas entre pacientes e habitantes. Além disso, sua inspiração se encontrava nas experiências com cooperativas de trabalhadores espanhóis, o que deixa entrever que a experiência do trabalho era dotada de um valor significativo em suas propostas terapêuticas.

Há, parece-nos, nas formulações de Tosquelles, a operação de um deslocamento ético do poder autoritário do saber médico ao ressaltar que em atividade e, inclusive em atividade de trabalho, os pacientes catalisavam elementos analíticos capazes de fazer questão às institucionalidades estabelecidas. Tosquelles opera com o conceito de atividade para trabalhar no plano institucional.

As contribuições de Franz Fanon em Saint Alban foram ressaltadas e louvadas por Tosquelles, em texto publicado em 1975, no qual destaca a importância desse psiquiatra afrocaribenho na psicoterapia institucional, em 1953. Tosquelles salienta sua capacidade de problematizar as questões do cotidiano hospitalar, em especial, no que dizia respeito à liberdade do outro, atuando a partir de uma "fraternidade efetiva", que tinha como marca o acolhimento e a afirmação da diferença.

Assim, consoante com a proposta da psicoterapia institucional, assumia uma postura e um compromisso críticos, colocando em questão as hierarquias de saberes médicos muito comuns em hospitais psiquiátricos. Fanon trabalhava em Saint-Alban de forma a oferecer possibilidades da loucura de falar e reelaborar-se. "Pensava Saint-Alban como um tipo de 'reserva natural' onde se poderia respirar ar puro, como um castelo subtraído dos desafios impostos pela civilização industrial ou pela sociedade de consumo" (TOSQUELLES, 2017, p.224). ${ }^{6}$

Ruiz, Athayde, Nogueira Filho, Zambroni-de-Souza e Athayde (2013) analisam as contribuições de Tosquelles ao campo da saúde mental destacando sua influência no campo da clínica do trabalho. Tosquelles trouxe ao debate a importância do trabalho como experiência

\footnotetext{
${ }^{6}$ Se piensa a Saint-Alban como haciendo un espacio -un hospital psiquiátrico- un nuevo tipo de "reserva natural" donde se respiraba el aire puro de la montaña; también era una "campiña" o un "castillo" sustraído de los desafíos impuestos por la civilización industrial o la sociedad de consumo.
}

Periódico Horizontes - USF - Itatiba, SP - Brasil - e021032 
cuja função psicológica e social merecia ser explorada.

Na psicoterapia institucional, a atividade de trabalho se convertia em possibilidade de intervenção (terapêutica), colocando em cena mais do que as histórias pessoais dos internados, valorizando aquilo que era experimentado nas situações concretas de vida e de trabalho. Além disso, o internado passava a atuar como coprodutor do serviço, possibilitando uma clínica que contava com a inventividade dos pacientes convocada em situações de trabalho, situando o procedimento clínico nas linhas problemáticas que se abrem nessas situações.

Pelo conceito de atividade, colocavam-se questões peculiares no que tange ao aspecto relacional entre equipe de saúde e portadores de sofrimento psíquico, o que permitia uma ampliação da análise dos modos de relação que se estabelecem entre equipe de saúde e usuários de serviços em saúde mental. Ligam-se o trabalho clínico e o institucional, na medida em que, a partir do conceito de atividade, as práticas em saúde mental chegariam a seu termo por uma transformação, ao mesmo tempo, de usuários, de trabalhadores em saúde mental e de processos organizacionais e institucionais vividos em modos de trabalhar nos serviços (AMADOR, 2009).

Clot (2013b) destaca três importantes contribuições de François Tosquelles à clínica do trabalho: a presença do conceito de atividade, a noção de clínica e as questões relativas aos conceitos de instituição e de coletivo, presentes em suas formulações. Diz Clot que Tosquelles deixou um instigante legado ao campo da análise do trabalho, ainda que indiretamente, sobretudo, quando colocou em questão a prática da Ergoterapia nos hospitais psiquiátricos, nos anos 60 .

Sua preocupação se dirigia ao que se passava com os internos do hospital, quando estes estavam fazendo algo, ao invés de apenas "ocupá-los" com algo a fazer, como se pretendia na Ergoterapia. Assim, colocava em cena a atividade, esfera que porta elementos para promover a crítica do hospital, tomado enquanto instituição. Havia, nessa perspectiva, no âmbito da atividade dos pacientes uma potência de fazer movimentar as esferas institucionalizadas, considerando a atividade como processo de renormatização parcial dos meios de vida, com dimensões poéticas, regidas pelo signo da criação como fonte permanente de invenção de novas formas de viver (SCHWARTZ, 2000; CLOT, 2010).

Se tomarmos o conceito de instituição como sistema organizado de meios (DELEUZE, 2005), essa afirmação ganha ainda mais sentido, uma vez que, nesse caso, a instituição seria algo 
da ordem de uma estabilização provisória e precária daquilo que emerge da atividade. A atividade catalisa algo que é da ordem de uma experiência normativa que envolve transformação de si e do meio, sobretudo, uma transformação de si na criação de meio, e não somente aplicação de representações funcionais às demandas do processo produtivo.

Clot (2013b) observa, ainda, que para Tosquelles é fazendo as coisas que o homem faz a si mesmo e é convertendo o meio em mundo - em um processo que entendemos como criação de possíveis -, recriando-o, que pode viver, para além de se adaptar ou morrer. Nesses termos: "a possibilidade de que uma atividade ou um trabalho terapêutico sejam eficientes estará em relação direta com a quantidade de iniciativa e de atividade própria que um doente poderá pôr em jogo" (CLOT, 2013b, p.200). Tal iniciativa refere-se, principalmente, a uma dimensão insubordinada, já que a atividade não consiste em um agir por consentimento à norma. Trata-se de uma "construção, no comum, de um mundo em que o sujeito pode viver a experiência do real naquilo que ele tem de desconhecido e inesperado. No acontecimento, ele reencontra, graças à instituição, o poder de agir sobre seu meio, contra a instituição e além da instituição" (CLOT, 2013b, p.201).

Assim, Tosquelles sustenta a atividade como instrumento clínico, ele "convoca certa 'Ergologia'" (CLOT, 2013b, p.201). Na prática da Ergoterapia, isso é algo que Schwartz (2000) sustenta como sendo muito próprio das atividades humanas que dizem respeito às (re)singularizações parciais, inerentes às situações de trabalho. $O$ trabalho, mais do que promover certa anestesia ou efeito calmante sobre os internos do hospital, poderia dirigi-los ao vivo, pela ação, o que se encontra no cerne das abordagens clínicas do trabalho que tomam o trabalho como atividade. A concepção de clínica no pensamento de Tosquelles se situa justamente aí, na potência individual e coletiva dos trabalhadores de fazerem algo transformador de si e por si mesmos em um processo pelo qual fazem (trans)bordar a instituição ao conferir-lhe outros contornos e possíveis.

Nesse entendimento, trabalhar promove uma tessitura de instituições e é por trabalho coletivo que se atinge sua vitalidade. Um trabalho que se faz no enfrentamento do real, em experimentação de suas provas, afetando a organização oficial do trabalho e por essa via encontrando possibilidades de saúde no e pelo trabalho, experimentando um poder de agir que mais do que fazer coisas implica dar-Ihes a ser o que não eram (AMADOR; FONSECA, 2011). 
A influência de Tosquelles nas formulações da clínica da atividade está bastante presente nas elaborações realizadas por Clot (2013a; 2013b) a respeito do trabalho enquanto ofício. Isso porque:

[...] o coletivo está no indivíduo do mesmo modo que o inverso se verifica. 0 que os liga ou desliga é o desenvolvimento possível ou impossível de suas relações. Cada vez que 'encontramos' o coletivo, é porque ele foi recriado para além dele mesmo pela atividade própria de cada um (Tosquelles, 2009). 0 coletivo, visto sob esse ângulo, não é um resíduo do passado. Nos movimentos contemporâneos, a palavra 'ofício' revive e pode reviver em grande escala nas organizações como um verdadeiro operador de saúde. Mas o coletivo e mesmo o coletivo incorporado não recobre o todo do ofício. Se o ofício não se sustenta ele tampouco se esconde nas 'comunidades de práticas' locais ou no corpo de cada um. O ofício se faz também na atividade (CLOT, 2013a, p.10).

Cuidar do ofício seria o caminho para cuidar da saúde: trata-se de cuidar do trabalho para cuidar dos trabalhadores e trabalhadoras. Assim, Clot ressalta a dimensão de que o cultivo do trabalho como ofício implica um movimento pelo qual aqueles que trabalham lidam com diferentes instâncias, as quais se referem a planos prescritos, a modos como damos expressão ao trabalho por nossos atos, a dimensões relativas ao gênero profissional - esse um patrimônio relativo ao savoir-faire criado pelos trabalhadores em atividade - e, ainda, ao plano das relações com aqueles com os quais trabalhamos, os destinatários de nosso trabalho.

O que Yves Clot alerta é que, nessa dinâmica, assumimos enfrentar riscos, riscos de gerir uma dimensão não antecipável do trabalho, ainda que por entre esferas antecipáveis relativas às dimensões do prescrito e do gênero de atividade. Atingir a saúde pelo trabalho passa por experimentar essa possibilidade de exercermos nosso poder de agir, nosso poder de estabelecer novas relações entre os elementos e os processos, recriando a nós mesmos e ao trabalho. Há nessa dinâmica riscos de perturbar as instituições que, materializadas em modos de trabalhar, tendem a certa conservação, mas guardando uma relação de flerte com uma esfera instituinte que pede passagem.

Por entre normas vitais e normas sociais, trabalhamos. Por entre normas que dizem respeito à expansão da potência de existir e normas que regulam e controlam, trabalhadores e trabalhadoras enfrentam problemas práticos mediante um exercício de problematização capaz de movimentar as esferas instituídas nos planos do pensamento, das práticas e das organizações. 
Retornando uma indagação inicial deste texto: o que quer a Análise Institucional? Respondemos, juntamente com outros e outras institucionalistas, que quer produzir novos problemas. Nessa resposta acrescentamos a pergunta: o que querem as clínicas do trabalho? Temos aí um encontro fértil de perspectivas.

Em que pesem as diferenças de abordagem entre as referências clínicas do trabalho, querem elas ativar a potência dos coletivos de transformar suas vidas mediante interferência nos arranjos relativos às condições e à organização do trabalho, bem como à produção de subjetividade e saúde. Assim sendo, a análise de implicação, que emerge no escopo da Análise Institucional como ferramenta-chave (LOURAU, 1993; GUATTARI; ROLNIK, 2013), encontra-se também em nosso ponto de vista como ferramenta-chave no escopo do procedimento clínico (do trabalho).

A análise da atividade não procede nem por dedução, nem por indução. Não é deduzida dos passos operacionais do trabalho, tampouco é efeito de indução do entendimento. Não é explicativa. Em diálogo com o real da atividade ela produz novos sentidos. Ela procede por implicação, pensamos. Por um movimento no plano do pensamento que se sustenta no plano móvel da incessante problematização. Problematizar aqui consiste mais em escapar da institucionalização do pensamento mediante um movimento de colocação de problemas que permita soluções inventivas do que reiterar nossa pretensa posse de regras de solução. Tal é o movimento que experimentamos quando da experiência do trabalho como atividade, tal é a potência do trabalho para promover novidade no plano das subjetividades, saúde e crítica institucional em um processo que envolve poder de ação coletiva.

A metodologia em clínica da atividade tem por objetivo o desenvolvimento do poder de agir dos trabalhadores. Para alcançar esse objetivo, precisa desenvolver também seu próprio poder de agir, como uma vertente da psicologia, mais especificamente da psicologia do trabalho.

\section{A análise de implicação e as preocupações ético-políticas da clínica da atividade}

Desde os primeiros escritos, a clínica da atividade visa ao desenvolvimento do poder de agir dos profissionais sobre seu meio, já que considera, acompanhando o que já vinha sendo afirmado por Ivar Oddone, que as transformações desejadas só são consistentes se elas se dão 
por iniciativa dos próprios trabalhadores (CLOT; FAÏTA, 2000). A clínica da atividade orienta sua atividade para os coletivos de trabalho, buscando assim revitalizar a instância transpessoal do ofício em foco.

No mesmo artigo citado, os autores apontam qual seria inicialmente a função do trabalhador que demanda a intervenção e do especialista que responde a essa demanda.

De fato, hoje podemos considerar que as transformações só são duravelmente sustentadas pela ação dos próprios coletivos de trabalho. Por isso, parece-nos que a análise do trabalho visa inicialmente a assessorar esses coletivos em seus esforços para redobrar seu poder de agir em seu meio. Dito de outro modo, para ampliar seu raio de ação. A ação transformadora durável não poderia ser delegada a um especialista da transformação, já que não pode se tornar um simples objeto de experts sem graves decepções para os demandantes (CLOT; FAÏTA, 2000, p.8). ${ }^{7}$

No diálogo que irá se estabelecer entre clínico e trabalhador, é preciso que o primeiro esteja atento ao fato de que existem linguagens de ofício que o clínico da atividade não conhece, ou pouco conhece, e necessita se posicionar como alguém que irá aprender sobre o ofício com aquele que tem de fato conhecimento desse ofício, sobretudo, por ter dele experiência. 0 objetivo é pôr em palavras o ofício, discuti-lo com o trabalhador, sem pôr palavras em sua boca, sem falar por ele.

Os autores explicitam, com referências teóricas que não são as mesmas da análise institucional, preocupações pertinentes às relações de poder e à dominação que podem se configurar nas relações do pesquisador com o campo. Em suas palavras:

Deve-se então evitar impor apesar de tudo um modo de agenciamento de formas verbais, privilegiar tacitamente 'um regime social de funcionamento da língua' [...] e sobretudo transformar em dominação - mesmo que inconscientemente - certas relações pré-construídas e disponíveis no discurso científico entre língua e fora da língua.

Tratar-se-ia nesse caso da imposição de um duplo gênero: um gênero do discurso e também o gênero técnico próprio a nossa esfera de pesquisa. 0

\footnotetext{
${ }^{7}$ En effet, on peut aujourd'hui considérer que les transformations ne sont portées durablement que par l'action des collectives de travail eux-mêmes. C'est pourquoi il nous semble que l'analyse du travail vise d'abord à seconder ces collectifs dans leurs efforts pour redéployer leur pouvoir d'agir dans leur milieu. Autrement dit pour élargir leur rayon d'action. L'action transformatrice durable ne saurait donc être délégué à un spécialiste de la transformation, laquelle ne peut devenir, sans graves mécomptes pour les demandeurs, un simple objet d'expertise.
}

Periódico Horizontes - USF - Itatiba, SP - Brasil - e021032 
segundo propõe esquemas de discriminação pelos quais elementos e relações serão destacados e valorizados, ou ao contrário reprimidos, minimizados (CLOT; FAїTA, 2000, p.23-24). ${ }^{8}$

No encontro que se dá entre as referências teóricas da clínica da atividade e da análise institucional, há um deslocamento: objetiva-se produzir novas práticas, sublinhando o instituído como importante fonte de recursos para os movimentos instituintes. Tornou-se possível retomar as referências da análise institucional e da saúde do trabalhador e fertilizá-las, inventar nesse campo novas normatizações. E o acidente de trabalho, objeto de estudo desde os tempos da psicologia industrial e da medicina de fábrica, pode ser tomado como disparador de instalação de um analisador construído.

Lançar mão de velhas experiências para viver novas experiências surge como um caminho alvissareiro. No intuito de contribuir para as ações em saúde do trabalhador, de modo a não cair no higienismo nem na banalização dos perigos efetivamente existentes nos meios de trabalho, nem sempre elimináveis, buscamos fabricar dispositivos de análise do trabalho em que os trabalhadores possam ser protagonistas dessa análise. Dizendo de outro modo, na construção de dispositivos de pesquisa-intervenção, buscamos pesquisar com os trabalhadores, usando analisadores construídos de um modo que segue também os princípios metodológicos propostos pela clínica da atividade.

Acompanhando a formulação da Análise Institucional, consideramos que todo processo de pesquisa intervém, participa da produção de uma realidade que não é jamais estática e acabada (LOURAU, 1993). Essa participação que o pesquisador e a pesquisadora têm, na produção da realidade que pesquisa, deve ser sempre analisada. Utilizando conceitos da clínica da atividade, pode-se dizer que a pesquisa é um novo gênero profissional que se cruza com os já existentes no ambiente pesquisado, produzindo novas estilizações que realimentam o gênero de atividade do ofício em análise.

\footnotetext{
8 II faut pour cela se garder d'imposer malgré tout un mode d'agencement des formes verbales, de privilégier tacitement un régime social de fonctionnement de la langue, comme on l'écrit plus haut, et surtout de transformer en domination - fût-elle inconsciente - certains rapports pré-construits et disponibles dans le discours scientifique entre langue et hors-langue.

C'est de l'imposition d'un double genre qu'il s'agitait : un genre du discours et aussi le genre technique propre à notre sphère de recherche. Le second propose les schèmes discriminants par lesquels éléments et rapports seront distingués et mis en valeur, ou au contraire refoulés, minorés.
} 
Concebemos o trabalhador como um ser em movimento, capaz de imprimir algo seu naquilo de que participa, capaz de intervir em sua própria história; o trabalho como um processo coletivo e singular, de criação e recriação da história de um ofício; e a atividade de trabalho como processo de produção não só de coisas ou serviços, mas também de subjetividades. Nesse processo, o conhecer é inseparável do transformar.

\section{Racializar a clínica do trabalho: um efeito de análise institucional}

A dimensão racializada da experiência ocupa um lugar ainda pouco estudado nas pesquisas em clínicas do trabalho. Trata-se de discutir como a negritude e a branquitude (BENTO, 2002) compõem a produção do ofício, expressando uma peculiar dinâmica que envolve reconhecimento e poder de agir, uma vez que a modernidade tem negado o agenciamento político às pessoas classificadas como inferiores, em função da divisão sexual ou racial do trabalho.

O Brasil, sendo um país marcado pela escravidão, necessita que as produções científicas no âmbito das clínicas do trabalho considerem essa especificidade histórica, que tende a se atualizar na história dos ofícios. Não há como debater essa temática sem tomarmos o processo de escravização como uma parte relevante, visto que deixou marcas no modo como se organizam as relações de trabalho, das quais têm sido apontadas, sobretudo, as maneiras como negros e negras se inserem no mercado de trabalho (CARDOSO, 2008).

A perspectiva analítica do marcador de raça na esfera do trabalho, pela via das microgestões laborais, oferece potentes elementos para o enfrentamento do racismo estrutural e institucional no âmbito do trabalho. Como bem disse Mbembe (2017), o negro escravizado tem sido tomado como uma mercadoria e não reconhecido como um sujeito.

Esse longo processo de escravização tem como marca uma constante reatualização de práticas de violência racista, que tomam contornos de um racismo estrutural, ou seja, como um componente orgânico presente nas tramas sociais (ALMEIDA, 2018). Essa história dirá das possibilidades de participação dos trabalhadores negros e negras na composição dos diversos ofícios; possibilidades essas marcadas pela posição de uma existência subalterna.

Assim, racializar a clínica do trabalho é trazer para o debate como a composição entre as 
práticas de violência racista amparadas pelos discursos da branquitude e a presença dos corpos dos trabalhadores negros e negras compõem o ofício: como se dá a composição da história do ofício? Como se dá o embate entre a branquitude e ações antirracistas na composição do gênero profissional e das estilizações no trabalho?

Acreditamos que apontar a emergência dessa discussão é tomar uma posição ativa no enfrentamento ao racismo no âmbito do trabalho. Essa posição ativa só se faz possível na produção de discursos e práticas que se afirmem no compromisso da produção de narrativas que não sejam eurocentradas. Nesse sentido, é pelo processo de descolonização dos saberes que se faz possível ampliar as discussões de problemáticas que não haviam sido apontadas até o momento.

Fazer da clínica da atividade o caso, aquilo a ser pensado do ponto de vista de seus arranjos enquanto produção institucional leva-nos a pensar que o silêncio desta abordagem no que tange a questões de raça se deve às forças de constituição da colonização no plano da produção e conhecimento. Em que pese a interessante marca dessa abordagem, a qual por se constituir na tradição europeia coloca em evidência elementos da ordem da dimensão coletiva e política da experiência, diferentemente das abordagens de linhagem norte-americana de teor individualista nas análises que se referem ao campo do trabalho, a não consideração das questões raciais nas suas questões clínicas e de pesquisa nos parecem um analisador.

Spivak (2010), com o seu conceito de violência epistêmica, auxilia-nos a problematizar o silenciamento a respeito das questões raciais. Para essa autora, essa prática de violência se apresenta pela negação de outras narrativas que não sejam a do colonizador; seria um mecanismo de silenciamento dos sujeitos tomados como subalternos. Esse silenciar pode dar-se de diversas maneiras - desde a não escuta até a desvalorização dos saberes produzidos por determinados grupos étnicos - num processo permanente de mantê-los numa posição de subalternos para que possam perpetuar os privilégios dos que são autorizados e legitimados à produção de saberes - posição essa ocupada pelos povos colonizadores.

Pontuamos que os discursos e saberes produzidos pelos sujeitos subalternizados não são apenas um contradiscurso aos saberes eurocentrados, mas produções pensadas a partir de outras referências (RIBEIRO, 2017). É a partir desses saberes que se faz possível o movimento de descolonizar o pensamento, possibilitando que se avance em discussões que só recentemente 
vêm sendo pautadas. Descolonizar o pensamento é compor com estudos que já foram produzidos, em um movimento de tessitura com referências epistêmicas que permaneciam silenciadas e invisibilizadas.

Nesse movimento de produção de intercessões entre clínica da atividade e teóricos descoloniais, nasceu uma pesquisa com professoras negras que atuam na educação pública estadual do Rio Grande do Sul. A pesquisa desenvolvida pelo N-pista(s) - Núcleo de pesquisas Instituições, Subjetivação e Trabalho em Análises(s) propõe construir com essas professoras espaços de coanálise do trabalho enquanto atividade, tendo atenção à questão racial que se faz presente na composição das microgestões que essas trabalhadoras efetuam no trabalho em situação. Esse estudo tem nos apontado alguns pontos da clínica da atividade que carecem de desenvolvimento.

Ao narrarem a atividade, as professoras participantes do estudo trazem, com muita força, os deslocamentos que realizam diariamente, em um processo de composição com alguns alunos, para trazer para o debate a discussão racial, tendo em vista que essa temática não é pautada por todos os professores, ou seja, não é tomada como algo que compõe o gênero profissional. A estratégia de compor com os alunos tem se mostrado como uma possibilidade de se manterem em atividade, em um fazer comprometido eticamente.

A experiência de solidão é compartilhada nas narrativas ao longo de toda a trajetória profissional, ocupando essas trabalhadoras uma posição à margem dos seus pares. Essa posição marginal surge na recusa pelos pares em estabelecer parcerias, a recusa em participar das ações planejadas por elas e a recusa em reconhecer práticas de violência racista que acontecem no cotidiano do trabalho. A pesquisa, ainda em andamento, vem mostrando que o gênero profissional e as estilizações se sustentam e sustentam discursos racistas, atualizando valores da branquitude.

Compor a discussão racial - com teóricos negros e negras - com os operadores conceituais da Clínica da Atividade tem nos possibilitado ampliar a problematização na direção de uma clínica do trabalho comprometida com o enfrentamento das práticas racistas que ancoram as relações que se estabelecem no âmbito do trabalho. Dentre os aspectos que vêm sendo discutidos com as trabalhadoras em pesquisa, destaca-se a experiência da solidão por parte de professoras negras que, ao serem invisibilizadas por seus pares, recorrem a recursos 
para agir que nem sempre são aqueles reconhecidos como compondo o gênero de atividade profissional. Dito de outro modo, temos discutido nessa pesquisa que o gênero profissional pode sustentar lógicas racistas, bem como estar nelas sustentado. Consideramos a análise do trabalho como atividade meio, por seu caráter eminentemente problematizador, para investimento em uma clínica antirracista do trabalho.

Em clínica da atividade, considera-se que o desenvolvimento se faz pela atividade sobre a atividade. No caso do desenvolvimento da atividade clínica, cabe uma clínica da clínica, para o desenvolvimento de nossos recursos para a ação. A análise institucional, com suas ferramentas conceituais, constitui-se em um poderoso dispositivo para essa clínica da clínica.

Seguindo no percurso de pesquisa e realizando a intervenção no campo da psicologia do trabalho, a fecundidade deste e de outros entrelaçamentos teóricos que podem ser feitos contribui para o desenvolvimento do campo. O processo de formulação da pesquisa-intervenção aprofunda a ruptura com os enfoques tradicionais de pesquisa e amplia as bases teóricometodológicas das pesquisas participativas, enquanto proposta de atuação transformadora da realidade sociopolítica, já que propõe uma intervenção de ordem micropolítica na experiência social.

As ferramentas da Análise Institucional nos permitem colocar a própria Clínica da Atividade em análise enquanto instituição, permitindo abrir questionamentos relativos ao alcance de suas problemáticas e abertura de novas questões clínicas, tais como as questões raciais.

\section{Referências}

ALMEIDA, S. O que é racismo estrutural? Belo Horizonte: Letramento, 2018.

AMADOR, F. S. Análise da atividade como prática clínico-institucional nas práticas em saúde mental. 2009. Disponível em:

http://www.abrapso.org.br/siteprincipal/images/Anais_XVENABRAPS. Acesso em: 19 out. 2020.

AMADOR, F.; FONSECA, T. M. G. Atividade: o trabalho sob o signo do inacabamento. In: ROSEMBERG, D. S., RONCHI FILHO, J.; BARROS, M. E. B. (orgs.). Trabalho docente e poder de agir: clínica da atividade, devires e análises. Vitória: EDUFES, 2011, p.19-50. 
BENTO, M. A. S. Pactos narcísicos no racismo: branquitude e poder nas organizações empresariais e no poder público. 2002, 185f. Tese (Doutorado em Psicologia) - Universidade de São Paulo, 2002. Disponível em: https://teses.usp.br/teses/disponiveis/47/47131/tde18062019-181514/publico/bento_do_2002.pdf. Acesso em: 19 out. 2020.

CANGUILHEM, G. O conhecimento da vida. Trad. Vera Lucia Avellar Ribeiro. Rio de Janeiro: Forense Universitária, 2012.

CARDOSO, A. Escravidão e sociabilidade capitalista: um ensaio sobre inércia social. Novos Estudos CEBRAP, n.80, p.71-88, 2008.

CLOT, Y. Le travail entre fonctionnement et développement. Bulletin de Psychologie, v.57, n.1469, p.5-11, 2004.

CLOT, Y. La recherche fondamentale de terrain : une troisième voie. Éducation Permanente, v.177, n.4, p.67-77, 2008.

CLOT, Y. Trabalho e poder de agir. Trad. Guilherme João F. Teixeira e Marlene M. Z. Vianna. Belo Horizonte: Fabrefactum, 2010.

CLOT, Y. O ofício como operador de saúde. Cadernos de Psicologia Social do Trabalho, v.16, n. especial, p.1-11. 2013a.

CLOT, Y. A contribuição de Tosquelles à clínica do trabalho. Trad. Cláudia Osório da Silva. Trabalho \& Educação, Belo Horizonte, v.22, n.1, p.199-208, jan./abr. 2013b.

CLOT, Y.; FAITA, D. Genres et styles en analyse du travail. Concepts et méthodes. Travailler 4, p.7-42, 2000.

DELEUZE, G. Conversações. Trad. Peter Pál Pelbart. Rio de Janeiro: Ed. 34, 1992.

DELEUZE, G. Bergson, 1859-1941. In: ORLANDI, L. B. (orgs). A ilha deserta e outros textos. Trad. Lia Guarino. São Paulo: Iluminuras, 2005, p. 13-19.

GUATTARI, F; ROLNIK, S. Micropolítica: cartografias do desejo. Petrópolis: Vozes, 2013.

LOURAU, R. Análise institucional e práticas de pesquisa. Rio de Janeiro: UERJ, 1993.

MBEMBE, A. Políticas da inimizade. Trad. Sebastião Nascimento. São Paulo: n-1edições, 2021.

ODDONE, I.; RE, A., BRIANTE, G. Redécouvrir l'expérience ouvrière : vers une autre psychologie du travail? Trad. Marie-Laure Barsotti. Paris, Messidor, 1981.

OSORIO DA SILVA, C. Psychologie du travail: la santé comme choix éthique. In: LACOMBLEZ, M. (coord.). (Re)découvrir la psychologie du travail au Brésil. Toulouse: Octarès, 2020, p.83-103. 
OSORIO DA SILVA, C. Pesquisa e intervenção: movimentos que se cruzam e coexistem, em mútua interferência. In: BANKS-LEITE; L., SMOLKA, A. L. B; DOS ANJOS, D. D. (orgs). Diálogos na perspectiva histórico-cultural: interlocuções com a Clínica da Atividade. Campinas: Mercado das Letras, 2016, p.153-168.

OSORIO DA SILVA, C.; ZAMBONI, J.; BARROS, M. E. B. Clínicas do trabalho e análise institucional. Rio de Janeiro: Nova Aliança Editora e Papéis, 2016.

RODRIGUES, H. C. B.; LEITÃO, M. B.; BARROS, R. D. B. Grupos e instituições em análise. Rio de Janeiro: Rosa dos Tempos, 1992.

RIBEIRO, D. O que é lugar de fala? Belo Horizonte: Letramento, 2017.

RUIZ, V. S.; ATHAYDE, V.; NOGUEIRA FILHO, I.; ZAMBRONI-DESOUZA, P. C.; ATHAYDE, M. François Tosquelles, sua história no campo da reforma psiquiátrica: desinstitucionalização e suas pistas para uma abordagem clínica do trabalho centrada na atividade. Estudos \& Pesquisas em Psicologia. v.13, n.3, p.855-877. 2013.

SCHWARTZ, Y. A comunidade científica ampliada e o regime de produção de saberes. Trabalho \& Educação, Belo Horizonte, n.7, jul/dez., p.38-46. 2000.

SPIVAK, G. C. Pode o subalterno falar? Trad. Sandra Regina G. Almeida, Marcos P. Feitosa e André P. Feitosa. Belo Horizonte: UFMG, 2010.

TOSQUELLES, F. Le travail thérapeutique en psychiatrie. Paris: Érès, 2009.

TOSQUELLES, F. Frantz Fanon en Saint-Alban (1975). Teoría y Crítica de la Psicología. n.9, p.223229. 2017. Disponível em: http://www.teocripsi.com/ojs/index.php/TCP/article/view/191/175. Acesso em: 14 out. 2020.

Recebido em outubro 2020.

Aprovado em março 2021. 